talle wird mit soviel von dem genannten Reagens versetzt, dass sie vollständig entfärbt ist und sodann zum Kochen erhitzt, wobei das Kupfer als schweres schwarzes Kupfersulfür sich abscheidet. Man kocht so lange, bis Klärung der überschüssigen Flüssigkeit eintritt, bis der ausgeschiedene Schwefel sich also zusammengeballt hat; hat man einen nicht zu grossen Ueberschuss des Fällungsmittels zugesetzt, so tritt die Klärung schon nach 3-5 Minuten dauerndem Kochen ein. Nach dem Abfiltriren und sorgfältigen Auswaschen wird das erhaltene Kupfersulfür in bekannter Weise mit Schwefel gemengt und im Wasserstoffstrom geglüht. Aus dem Filtrate wird das Cadmium nach einer der üblichen Methoden, entweder durch Fällung als Carbonat oder als Sulfid niedergeschlagen. Hervorzuheben ist, dass nach des Verfassers Angaben die Trennung in schwefelsaurer lösung leichter und sicherer auszuführen ist als in salzsaurer.

Die von Vortmann angeführten zahlreichen Belege sind sehr befriedigend.

\title{
Ueber die Scheidung des Cadmiums vom Zink durch Elektrolyse
} hat A. Yrer*) Mittheilungen gemacht. Eine elektrolytische Bestimmung des Zinks und Cadmiums war zwar bereits durch die Versuche von Riche, von Beilstein und Jawein, von Millot und von Edgard Smith ermöglicht, eine gleichzeitige Trennung vom Zink gestatten indessen die von den genamnten Autoren eingeschlagenen Wege nicht, da die beiden Metalle sich gleichzeitig abscheiden.

Die alleinige Abscheidung des Cadmiums dagegen und damit eine vollkommene Trennung desselben vom Zink, welches in Lösung bleibt, ist dem Verfasser in folgender Weise gelungen: Die Lösung von essigsaurem oder schwefelsaurem Cadmium- und Zinkoxyd wird mit $2-3 g$ kohlensaurem Natron and einigen Tropfen Essigsâure versetzt und alsdann nach dem Erwärmen in der von Riche**) für das Zink angegebenen Weise mittelst zweier Daniell'scher Elemente elektrolysirt. Nach der Abscheidung des Cadmiums, welches sich in krystallisirter Form am negativen Pole niederschlägt, ${ }^{* *}$ ) bringt man den Niederschlag in einen Tiegel, wäscht ihn zunächst mit Wasser, dann mit A.lkohol vollkommen aus, trocknet und wägt. In der das Zink ent-

*) Bull. soc. chim. de Paris 34, 18.

**) Vergl, diese Zeitschr. 17, 218.

***) Bei Anwendung von 0,180 bis $0,210 \mathrm{~g}$ Metall ist die Abscheidung in 3-4 Stunden beendigt. 
haltenden Lösung lässt sich dieses nunmehr ebenfalls elektrolytisch, nach dem Vorgange von $\mathrm{Riche}$, bestimmen.

Man könnte auch eine ammoniakalische, mit schwefelsaurem Ammon versetzte Lösung der beiden schwefelsauren Metallsalze der Elektrolyse unterwerfen; der Verfasser räth indessen von diesem Wege ab, weil er einen nicht genügend compacten Cadmiumniederschlag liefert.

Belege sind der Mittheilung nicht beigegeben.

Eine colorimetrische Bestimmungsmethode des Chlors im Bromkalium gründet Carl Roth*) auf die Thatsache, dass bei der Destillation von chlorhaltigem Bromkalium mit Schwefelsäure und chromsaurem Kali, eine dem vorhandenen Chlor entsprechende Menge Chromoxychlorid gebildet wird; beim Einleiten desselben in ammonhaltiges Wasser zerfällt es bekauntlich in Chlorammonium einerseits und chromsaures Ammon andererseits, welches letztere, je nach der vorhandenen Quantität, selbst verdünnten Lösungen einen sehr verschiedenen Färbegrad ertheilt. Dieser aber gestattet einen Rückschluss auf den Chlorgehalt der untersuchten Bromkaliumprobe.

Um die Bestimmung auszuführen, wird $1 g$ des Untersuchungsmateriales mit ungefähr der gleichen Menge doppeltchromsauren Kali zusammengerieben und das Gemenge ohne Verlust in eine Flasche gebracht. Jetzt werden $5 c c$ concentrirte Schwefelsäure zugegeben, und das Ganze, nachdem die Flasche mit einer etwa $50 \mathrm{cc}$ einer sehr verdünnten Auflösung von Ammon in Wasser enthaltenden Vorlage verbunden worden, einer gelinden Erwärmung unterworfen. Dem Eintreten der Absorptionsflussigkeit in die Entwickelungsflasche wird durch zwei in das Ansatzrohr der Vorlage geblasene Kugeln vorgebeugt.

Nach Beendigung der Operation wird der Inhalt der Vorlage in einen Messcylinder gespült, darin auf $100 \mathrm{cc}$ Wasser verdünnt und nun der Vergleich mit gleich stark gefärbten Lösungen von neutralem chromsaurem Ammon vorgenommen. 152 Gewichtstheile dieses Salzes entsprechen 71 Gewichtstheilen Chlor. Wenn man also beispielsweise den Maximal-Chlorgehalt des Bromkaliums zu $5 \%$ oder zu $0,05 \mathrm{~g}$ auf $1 \mathrm{~g}$ annimmt, so ergibt sich aus der Proportion

$$
71: 152=0,05: \mathrm{x}
$$

diejenige Menge des chromsauren Ammons, welche in $100 \mathrm{cc}$ Wasser gelöst werden muss, um eine 5 procentige Lösung, resp. deren Färbung

*) Chem. News 43, 60 . 